\title{
BMJ open Do men consult less than women? An analysis of routinely collected UK general practice data
}

\author{
Yingying Wang, ${ }^{1}$ Kate Hunt, ${ }^{1}$ Irwin Nazareth, ${ }^{2}$ Nick Freemantle, ${ }^{2}$ Irene Petersen ${ }^{2}$
}

To cite: Wang $\mathrm{Y}$, Hunt $\mathrm{K}$, Nazareth I, et al. Do men consult less than women? An analysis of routinely collected UK general practice data. BMJ Open 2013;3: e003320. doi:10.1136/ bmjopen-2013-003320

- Prepublication history for this paper is available online. To view these files please visit the journal online (http://dx.doi.org/10.1136/ bmjopen-2013-003320)

Received 31 May 2013 Revised 17 July 2013 Accepted 19 July 2013

\footnotetext{
${ }^{1}$ MRC|CSO Social \& Public Health Science Unit, University of Glasgow, Glasgow, UK

${ }^{2}$ Department of Primary Care and Population Health, University College London, London, UK
}

\section{Corresponding to}

Dr Yingying Wang; ywang@ sphsu.mrc.ac.uk (Ying-Ying. Wang@glagow.ac.uk)

\begin{abstract}
Objective: To examine whether gender differences in primary care consultation rates (1) vary by age and deprivation status and (2) diminish when consultation for reproductive reasons or common underlying morbidities are accounted for.
\end{abstract}

Design: Cross-sectional study of a cohort of patients registered with general practice.

Setting: UK primary care.

Subjects: Patients (1 869149 men and 1916898 women) registered with 446 eligible practices in 2010.

Primary outcome measures: Primary care consultation rate.

Results: This study analyses routinely collected primary care consultation data. The crude consultation rate was $32 \%$ lower in men than women. The magnitude of gender difference varied across the life course, and there was no 'excess' female consulting in early and later life. The greatest gender gap in primary care consultations was seen among those aged between 16 and 60 years. Gender differences in consulting were higher in people from more deprived areas than among those from more affluent areas. Accounting for reproductive-related consultations diminished but did not eradicate the gender gap. However, consultation rates in men and women who had comparable underlying morbidities (as assessed by receipt of medication) were similar; men in receipt of antidepressant medication were only $8 \%$ less likely to consult than women in receipt of antidepressant medication (relative risk (RR) $0.916,95 \% \mathrm{Cl} 0.913$ to 0.918 ), and men in receipt of medication to treat cardiovascular disease were just $5 \%$ less likely to consult ( $R R=0.950,95 \% \mathrm{Cl} 0.948$ to 0.952 ) than women receiving similar medication. These small gender differences diminished further, particularly for depression (RR=0.950, 95\% Cl 0.947 to 0.953 ), after also taking account of reproductive consultations.

Conclusions: Overall gender differences in consulting are most marked between the ages of 16 and 60 years; these differences are only partially accounted for by consultations for reproductive reasons. Differences in consultation rates between men and women were largely eradicated when comparing men and women in receipt of medication for similar underlying morbidities.

\section{INTRODUCTION}

Average life expectancy is shorter for men than for women in almost all countries, but

\section{ARTICLE SUMMARY}

\section{Article focus}

- To examine gender differences in consulting in primary care in the UK population using routinely collected general practice data.

- To explore whether gender differences remain when consultation for reproductive reasons or treatment for common underlying morbidities are accounted for.

- To contribute current evidence on gender difference in health service use.

\section{Key messages}

- On average, men consulted less than women between the ages of 16 and 60 years, but not at younger and older ages.

- After controlling for medication for common underlying morbidities (depression and cardiovascular disease), gender differences in the use of primary healthcare services reduce substantially and are modest.

Strengths and limitations of this study

- The use of a UK-wide primary care database and the very large study population which is representative of the UK population, enabling a national picture of consultation pattern.

- The limited completeness of data recording on variables which may influence gender differences in consultation patterns, such as ethnicity and employment status. Using general practitioner recorded data, it is likely that regular users are over-represented in the analysis.

the magnitude of this advantage for women varies geographically and historically, highlighting the importance of understanding what causes gender differences in health. Although biological factors ${ }^{1}{ }^{2}$ and health behaviours $^{3} 4$ may provide a partial explanation, it is very widely assumed that men and women have a different propensity to consult $^{5}$ and that this may be an important contributor to the gender gap in mortality. ${ }^{6}$

Many large-scale studies based on survey data have reported greater use of primary healthcare services in women. ${ }^{7-11}$ In the UK, for example, women aged 16-44 years are 
twice as likely as men of the same age to have visited their general practitioner (GP) in the previous 12 months. ${ }^{12}$ This widely reported 'female excess' in consulting has led to an assumption that women are more willing to utilise health services in all circumstances and at all ages. However, existing evidence on gender and health service utilisation is mixed, ${ }^{13-17}$ and evidence comparing consultation patterns in men and women with similar morbidity is surprisingly sparse and weak. ${ }^{18} 19$ Qualitative research has indeed identified that men commonly express a reluctance to consult, $^{20} 21$ reinforcing a presumption that men may present with serious disease at a later (and less treatable) stage. Although very few gender comparative studies have been carried out in this area, there is evidence first that both men and women with high levels of multiple morbidity express reluctance to consult or over-use primary care resources, in the UK at least, ${ }^{22}$ and second, that some groups of men express a readiness to consult. ${ }^{23} 24$ As populations live longer with increasing health service needs, it is important to understand whether there are population subgroups who 'under-consult' or 'overconsult' to ensure the most effective use of primary care resources.

In the UK, general practice is usually the first point of access to formal health services, and about $90 \%$ of all NHS contacts take place in general practice, with nearly 300 million consultations a year. ${ }^{25}$ There has been an upward trend in GP consultation rates between 1995 and 2008, with higher rates recorded for women than men, except in those under 15 years and over 80 years. ${ }^{7}$ A similar pattern has been reported in other countries. $^{26-28}$ This may reflect greater medicalisation of women's lives during the reproductive years, gender differences in underlying morbidity, or a different propensity to consult about some kinds of symptoms. ${ }^{15} \quad 1629$ Despite the apparently consistent evidence for higher use of primary healthcare services in women, two important limitations to the evidence base remain. First, studies rely largely on self-reported survey data, and second there is a lack of attention to underlying morbidity. Indeed, research evidence on gender and utilisation of health services which use routine data sources is surprisingly scant in the UK and elsewhere.

The aim of this study is to use routinely collected primary care data from The Health Improvement Network (THIN) to explore contemporary consultation patterns in men and women in the UK. We examine whether gender differences in consultation rates are constant across the life course and across populations living in more or less affluent areas, and whether these differences remain after accounting for consultations related to reproduction and for two common underlying morbidities (depression and cardiovascular disease (CVD)).

\section{METHODS}

The Health Improvement Network (THIN) is one of the largest primary care data sources, consisting of electronic records of over 10 million patients from more than 500 practices in the UK. Participating practices are broadly representative of UK general practice for patients' demographic characteristics. ${ }^{30} 31$ THIN contains anonymised patient data directly extracted from practices using the Vision general practice system. It is a clinical database which includes every consultation between a health professional and a patient. Data are held on an individual's age, gender, registration details, clinical symptoms, medical diagnoses, laboratory tests, referrals and prescriptions. The level of consultation recording in THIN is comparable to that from other UK national data sources. ${ }^{32}$ THIN also includes an areabased deprivation index as a measure of patients' socioeconomic status. Each postal enumeration district (about 150 households) is assigned a Townsend deprivation score. These areas are divided into national quintiles and patients in THIN are assigned a quintile score.

To be included in the study, participating practices had to meet specific criteria, in relation to the completeness of data recording. The first criterion was that participating practices had acceptable computer use $^{33}$ : a practice on average continuously records at least one medical record, one additional health data record, and at least two prescriptions for each patient in each year. Second, practices' reporting on mortality rates must be consistent with their patients' demographic profile. ${ }^{34}$ Patients within eligible practices entered the study on the latest of three possible dates: the date of registering with the practice; the date when the practice provided acceptable mortality rates; or the date when the practice attained an acceptable level of data recording. Patients no longer contributed data from the date they were transferred out of the practice, or were recorded as having died, or when the practice has its last data collection.

For this study, we identified all direct contacts between clinicians and patients in primary care using Read codes, a hierarchical classification system that includes codes for signs and symptoms, diagnosis, procedures and investigations. ${ }^{35}$ A total of 83722 Read codes were included; these excluded 21138 codes which concerned records for patient and practice administration, provision of services, hospital procedures and operations. Consultations for reproductive reasons were also identified; these included all consultations related to normal and abnormal pregnancy, childbirth and postnatal consultations (including complications following childbirth and contraception). To further examine the effect of underlying morbidities on consultation rates among men and women, we identified patients who were in receipt of medication to treat depression and CVD as a clinical marker for patients with depression and CVD. These two conditions were selected as morbidities which (1) occur in both men and women, but there are gender differences in morbidity and mortality related to both conditions; (2) are common in adult life and (3) are treated within general practice. Hence, for each 
condition we considered patients to be actively undergoing treatment for depression or cardiovascular if they had received two or more relevant prescriptions. ${ }^{36}$ We chose to use prescription data rather than Read codes to identify patients with medical diagnoses of these conditions as we are aware that diagnoses are not consistently recorded by general practitioners; while some doctors record a diagnosis such as depression each time a patient consults, others will not include the diagnosis on the patient record for a consultation if it has been previously recorded, whereas medications are recorded more consistently. Furthermore, the issue of a prescription suggests that the underlying morbidity is sufficiently serious to warrant medication. We used a cut-off of two or more prescriptions as this group of people were more likely to be taking their medication rather than those who had only ever received one prescription.

\section{Statistical analysis}

We calculated the annual consultation rate in 2010, using number of consultations recorded and the number of person-years as the denominator. If a patient had more than one consultation within a day (whether face-to-face, over the telephone or home visits), we counted only one consultation for that day. We compared rates by gender, age groups and deprivation quintiles. We also calculated consultation rates which excluded all consultations for reproductive reasons (as noted earlier). In exploratory analyses (data not shown) we examined consultation rates for each of 3 years from 2008 to 2010; however, the patterns were very similar and we, therefore, focus here on consultations in the most recent year available, 2010.

In order to examine the effect on gender differences in consultation rates of taking account of common underlying morbidities, as described above, at an individual patient level we developed generalised Poisson mixed models, including patient age as a non-linear 5 knot restricted cubic spline, social deprivation (quintiles of Townsend scores) and gender. Practices were included as generalised random effects intercept terms. The $\log$ of the number of days followed in 2010 was included as an offset term. The model used a log link and Poisson/Gaussian error terms. We identified those who had at least one reproductive-related consultation in 2010 and examined the effect of inclusion of that term or exclusion of those subjects from our models. Furthermore, we identified patients who had at least two prescriptions of drugs for GVD or depression.

Analyses were conducted in Stata 12 and SAS $9.2 \times 64$ (SAS Institute, Cary, North Carolina, USA).

\section{RESULTS}

Consultation rate by gender, age groups and deprivation quintiles

In 2010, there were 1868149 men and 1916898 women registered with 446 eligible practices. Practice size varied widely ranging from 732 to 29779 (average practice size was 8487 ). The crude consultation rate was $32 \%$ less in men than in women: men consulted 3152 times/1000 person-years while women consulted 4607 times/1000 person-years (table 1 ).

The gender difference in consultation rates varied across the life course. As expected, we saw the largest difference in male and female consultation rates in the reproductive years, with a ratio of male-to-female consultation rate of 0.40 (95\% CI 0.392 to 0.404$)$ between the ages of 21 and 39 years (table 1 ). However, gender differences in primary care consultation rates were much narrower among the youngest (under the age of 21 years, rate ratio $=0.77,95 \%$ CI 0.760 to 0.780 ) and the oldest (over the age of 58 years, rate ratio $=0.92,95 \%$ CI 0.915 to 0.927$)$. Indeed, consultation rates in men and women in the oldest age group were quite similar, respectively $6308 / 1000$ person-years in men and 6851/1000 person-years in women.

Overall, consultation rates were higher among people living in the most deprived areas (5th quintile 3946 consultations/1000 person-years) than among those in the

Table 1 Crude consultation rate per/1000 person-year in 2010, by gender, age groups and deprivation

\begin{tabular}{|c|c|c|c|c|c|c|c|}
\hline & \multicolumn{3}{|l|}{ Men } & \multicolumn{3}{|l|}{ Women } & \multirow[b]{2}{*}{ M/F ratio $(95 \% \mathrm{Cl})$} \\
\hline & $\overline{\mathrm{N} /}$ & Person-year & Rate $(95 \% \mathrm{Cl})$ & No. I & Person-year & Rate $(95 \% \mathrm{Cl})$ & \\
\hline Overall & 5361100 & 1700883 & $3152(3149,3155)$ & 8001121 & 1736618 & $4607(4604,4610)$ & 0.68 (0.68 to 0.69$)$ \\
\hline \multicolumn{8}{|c|}{ Age quartiles } \\
\hline $0-20$ & 833499 & 415772.6 & $2005(2000,2009)$ & 1033997 & 396957.6 & $2605(2600,2610)$ & 0.77 (0.76 to 0.78$)$ \\
\hline $21-39$ & 705785 & 425352.9 & $1659(1655,1663)$ & 1766972 & 423892.6 & $4168(4162,4174)$ & 0.40 (0.39 to 0.40$)$ \\
\hline $40-57$ & 1225957 & 448215.3 & $2735(2730,2740)$ & 1914647 & 436238.1 & $4389(4383,4395)$ & 0.62 (0.62 to 0.63$)$ \\
\hline $58+$ & 2595859 & 411542.2 & $6308(6300,6315)$ & 3285505 & 479529.5 & $6851(6844,6859)$ & 0.92 (0.91 to 0.93$)$ \\
\hline \multicolumn{8}{|c|}{ Deprivation quintiles* } \\
\hline 1 & 1380470 & 432255.4 & $3194(3188,3199)$ & 1940611 & 440269.4 & $4408(4401,4414)$ & 0.72 (0.72 to 0.73$)$ \\
\hline 2 & 1176355 & 363717.9 & $3234(3228,3240)$ & 1699076 & 373145.0 & $4553(4546,4560)$ & 0.71 (0.70 to 0.72$)$ \\
\hline 3 & 1073696 & 343302.0 & 3127 (3122, 3133) & 1633282 & 351722.6 & $4644(4636,4651)$ & 0.67 (0.67 to 0.68$)$ \\
\hline 4 & 940676 & 302437.5 & $3110(3104,3117)$ & 1478517 & 308806.1 & $4788(4780,4795)$ & 0.65 (0.64 to 0.66$)$ \\
\hline 5 & 655705 & 212989.0 & $3078(3071,3086)$ & 1018719 & 211267.7 & $4822(4812,4831)$ & 0.64 (0.63 to 0.65$)$ \\
\hline
\end{tabular}




\begin{tabular}{|c|c|c|c|}
\hline & Men & Women & All \\
\hline $\begin{array}{l}\text { Number of patients who had at least one consultation } \\
\text { for reproductive reasons (\%) }\end{array}$ & $829(0.04)$ & 239594 (12.50) & 240423 (6.35) \\
\hline Age (median years) & 37.5 & 29.5 & 29.5 \\
\hline $\begin{array}{l}\text { Crude consultation rate per } 1000 \text { person-years } \\
(95 \% \mathrm{Cl})\end{array}$ & 5999 (5832 to 6169$)$ & 6283 (6272 to 6293 ) & 6282 (6272 to 6292$)$ \\
\hline Number of patients in receipt of medication for CVD (\%) & $221734(11.87)$ & 254831 (13.29) & 476565 (12.59) \\
\hline Age (median years) & 66.5 & 68.5 & 67.5 \\
\hline $\begin{array}{l}\text { Crude consultation rate per } 1000 \text { person-years } \\
(95 \% \mathrm{Cl})\end{array}$ & 9441 (9429 to 9454 ) & $\begin{array}{l}10180(10167 \text { to } \\
10192)\end{array}$ & 9836 (9827 to 9845$)$ \\
\hline $\begin{array}{l}\text { Number of patients in receipt of medication for } \\
\text { depression (\%) }\end{array}$ & $76602(4.10)$ & 173407 (9.05) & $250009(6.61)$ \\
\hline Age (median years) & 51.5 & 50.5 & 50.5 \\
\hline $\begin{array}{l}\text { Crude consultation rate per } 1000 \text { person-years } \\
(95 \% \mathrm{Cl})\end{array}$ & 9102 (9081 to 9124$)$ & 9961 (9946 to 9976) & 9698 (9686 to 9711$)$ \\
\hline
\end{tabular}

most affluent areas (1st quintile 3806 consultations/ person-years). However, there was a significant interaction between gender and deprivation status (accounting for gender as spline, and practices as random effects, $\mathrm{p}<0.001$ ); the gradient in consultation rates across deprivation quintiles was apparent in women, but not men.

\section{THE EFFECT OF REPRODUCTIVE CONSULTATIONS AND COMMON UNDERLYING MORBIDITIES ON GENDER DIFFERENCES IN CONSULTATION RATES}

More women $(n=239594)$ than men $(n=829)$ had consulted for reproductive reasons, and around twice as many were receiving antidepressant medication (women=173 407 and men $=76602$; table 2); the numbers of men and women who received cardiovascular medication were more similar (table 2). Gender differences in consulting rates among these three groups of patients were much smaller than those seen in the general population (table 1). For example, among people in receipt of medication for depression, the consultation rate was 9102/1000 personyear in men and 9961/1000 person-year in women. The differences in consultation rates between men and women were also reduced when reproductive-related consultations were excluded, although a considerable gap between male and female consultation rates remained between the ages of 15 and 60 years (figure 1 ).

Overall, after conditioning for age and deprivation quintile, there remained a substantial difference in consultation between men and women (relative risk (RR) 0.719, $95 \%$ CI 0.718 to 0.720 ; table 3 ). This was in part ameliorated when reproductive consultations were accounted for ( $\mathrm{RR}=0.81,95 \%$ CI 0.809 to 0.811$)$. When we further accounted for common underlying morbidities, the relative risks were much closer to unity: thus, after accounting for being in receipt of medication for depression the RR was 0.916 (95\% CI 0.913 to 0.918 ) and after accounting for being in receipt of medication for CVD the RR was 0.950 (95\% CI 0.948 to 0.952 ; table 3 ). In addition, gender differences in consulting became even smaller when reproductive consultations were also accounted for among those on antidepressant medications ( $\mathrm{RR}=0.951,95 \% \mathrm{CI}$ 0.948 to 0.954 ); additional adjustment for consultations for reproductive reasons had a little impact on gender differences in consulting for those with CVD.

\section{DISCUSSION}

This study examined the extent of gender differences in the use of primary care services in the UK over the life course and among people from different socioeconomic backgrounds, before and after taking account of consultations for reproductive reasons and two common underlying morbidities, CVDs and depression, as represented by being in receipt of medication for these conditions. Overall, as expected, we found that men's consultation rates were over $30 \%$ lower than women's, confirming the gender pattern in primary care consultations reported in earlier self-report surveys. ${ }^{11}$ The magnitude of gender differences in primary care consulting varied by age; there was very little difference in childhood and older age, and much higher rates of consulting in women than men during the reproductive and mid-life years. The variation in gender differences over the life course which we observed is very similar to that reported in another study using an alternative source of routinely collected data on primary care consultations in the UK. ${ }^{7}$ These studies together provide strong evidence that, on average during the working years men have fewer contacts with their general practitioners (GPs) than women do. It is often suggested that women's higher rates of health service contacts can be attributed to consulting for reproductive health, ${ }^{37}$ but in these data consultations for reproductive reasons only partially explained the large gap in consulting between men and women in mid-life, reflecting findings from small-scale studies using self-reported data. ${ }^{58}$ The gender difference in consulting also varied by deprivation status, reflecting a socioeconomic gradient in consulting rates among women but not men. This finding was unexpected and warrants further exploration. 
Figure 1 Consultation rate per 1000 person-year by gender and age (5 years age band) in 2010.

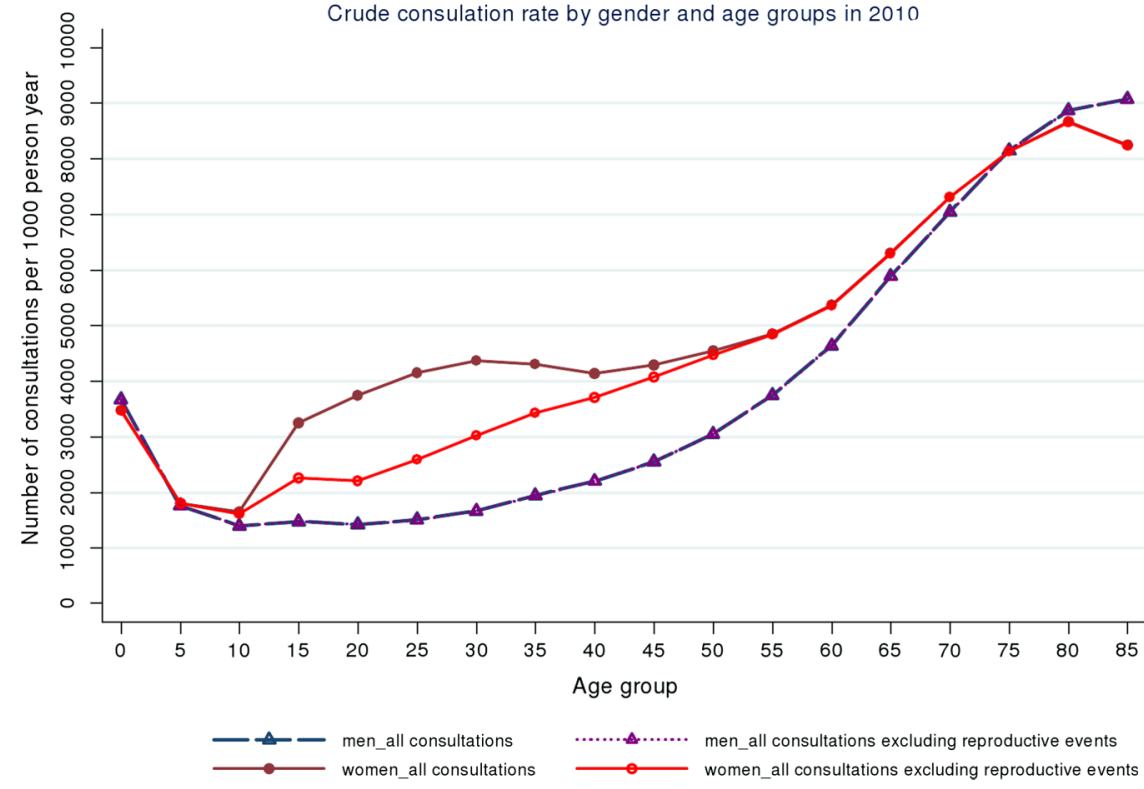

Another important finding of the study is that men and women with similar underlying morbidities (depression and CVD) differ much less in their use of primary healthcare services than men and women in the population as a whole. For this analysis, we choose two common conditions, which are usually managed by general practitioners, both of which differ by gender for morbidity and mortality. Compared to an overall male to female consultation rate ratio of 0.72 , the ratio was 0.92 for patients in receipt of medication for depression and 0.95 for patients in receipt of medication for CVD. This mirrors findings from smaller studies which have relied on self-reported data on morbidity and consulting, which suggest that gender differences in consulting are small after taking account of underlying morbidity. ${ }^{19} 39$ Our findings suggest that some of the 'excess' in female consulting may reflect greater levels of 'need' in relation to depression in women. However, given that we identified patients with depression through their medication records, it is important to note that previous studies have reported that women are more likely to receive a prescription when consulting their GPs. ${ }^{40}$ Well-designed experimental studies in the UK and the USA have shown how GPs take account of gender, ethnicity and age in assessing the likely importance of symptom presentations: given the same presentations of symptoms of coronary heart disease (CHD), GPs were more likely to attribute these to CHD in men and to have a higher level of certainty about their diagnosis. ${ }^{41-43}$ Although gender comparative evidence on consulting for other potentially fatal diseases is sparse ${ }^{44}$ a US study which compared the consulting histories of men and women diagnosed with colorectal cancer found that on average women delayed longer than men after first noticing their symptoms, and made more visits to the doctor before gaining their diagnosis. A recent UK study of a consecutive series of lung cancer patients at three Scottish hospitals found that gender was not a predictor of time from first noticing symptoms to consulting a GP. ${ }^{45}$

The strengths of this study include the use of a UK-wide primary care database and the large study population which is representative of the UK

Table 3 Gender differences in consultations adjusted for age and deprivation

\begin{tabular}{|c|c|c|c|}
\hline & Relative risk ( $95 \% \mathrm{Cl})$ & $\begin{array}{l}\text { Number of } \\
\text { males (\%) }\end{array}$ & $\begin{array}{l}\text { Number of } \\
\text { females }(\%)\end{array}$ \\
\hline All patients & 0.719 (0.718 to 0.720$)$ & $1868149(49.36)$ & $1916898(50.64)$ \\
\hline $\begin{array}{l}\text { Patients conditioning for consulting for reproductive } \\
\text { reasons }\end{array}$ & $0.810(0.809$ to 0.811$)$ & $1868149(49.36)$ & $1916898(50.64)$ \\
\hline Patients in receipt of medication for CVD & $0.950(0.948$ to 0.952$)$ & 221734 (46.53) & $254831(53.47)$ \\
\hline Patients in receipt of medication for depression & $0.916(0.913$ to 0.918$)$ & 76602 (30.64) & $173407(69.36)$ \\
\hline $\begin{array}{l}\text { Patients in receipt of medication for CVD and } \\
\text { adjusted for reproductive reasons }\end{array}$ & 0.957 (0.955 to 0.959$)$ & $221734(46.53)$ & $254831(53.47)$ \\
\hline $\begin{array}{l}\text { Patients in receipt of medication for depression and } \\
\text { adjusted for reproductive reasons }\end{array}$ & 0.950 (0.947 to 0.953$)$ & $76602(30.64)$ & $173407(69.36)$ \\
\hline
\end{tabular}


population, enabling a national picture of consultation pattern. However, there are also limitations which should be noted. The aim of this study was to explore the effect of gender on the use of primary care services after considering other confounding characteristics. We were not able to examine to what extent gender differences in consultation pattern are influenced by factors such as ethnicity and employment status because of limited completeness of data recording on these variables. Studies have shown the effect of ethnicity and gender concordance (similarity in gender of doctor and patients) on the use of services. ${ }^{46}{ }^{47}$ Second, our analyses focused on the utilisation of primary care health services, but were not able to examine fully the level of clinical needs. Third, THIN includes GP recorded data, which cover consultation information about patients who have been in contact with GPs or nurses, and it is likely that regular users are overrepresented in the analysis. Finally, as noted earlier, we included patients who had two or more prescriptions as a proxy for underlying morbidity, but this may have failed to identify patients with milder depression/CVD if their condition was not severe enough to warrant medication. In addition, some prescriptions such as antidepressants can be used to treat other conditions, such as chronic pain. While this is likely to occur relatively infrequently, if there are gender differences in these other conditions, this could differentially affect the specificity of controlling for use of that medication in relation to gender differences in consulting for the conditions of interest. Furthermore, if there is any difference in the compliance with medication by gender, with women being more likely to pick up a second prescription, then this could explain some of the diminution in gender differences in consulting when controlling for medication use.

Despite these limitations, this study provides much needed information on recent primary care use in men and women. It shows that gender differences in consulting are not universal; indeed the magnitude of gender differences are modest at some stages of the life course, and when account is taken of underlying morbidity.

\section{CONCLUSIONS}

Differences in consultations between men and women are most marked between the ages of 16 and 60 years, confirming that on average men have fewer contacts with general practitioners in early adulthood and mid-life, a difference that is only partially accounted for when consultations for reproductive health are considered. However, gender differences in consultations rates in patients in receipt of medication for CVD and depression are relatively small, suggesting that men and women with common morbidities may have more similar patterns of consulting. GPs need to be aware in planning their delivery of healthcare that the gender difference in primary care health service utilisation are not constant and do not simply reflect a greater and universal propensity for women to consult more readily than men.

Contributors KH originally conceived the study. YW extracted the data from the Health Improvement Network database and undertook the initial data analyses. NF conducted statistical analyses using Poisson mixed models. All authors contributed to the study design and decisions on the interpretation of results. YW and $\mathrm{KH}$ contributed to the drafting of the manuscript. All authors contributed to the critical revision of the manuscript and approved the final version prior to submission. $\mathrm{KH}$ is the guarantor.

Funding This study is funded by Medical Research Council.

\section{Competing interests None.}

Ethics approval This study received approval from EPIC Scientific Review Committee.

Provenance and peer review Not commissioned; externally peer reviewed.

Data sharing statement No additional data are available.

Open Access This is an Open Access article distributed in accordance with the Creative Commons Attribution Non Commercial (CC BY-NC 3.0) license, which permits others to distribute, remix, adapt, build upon this work noncommercially, and license their derivative works on different terms, provided the original work is properly cited and the use is non-commercial. See: http:// creativecommons.org/licenses/by-nc/3.0/

\section{REFERENCES}

1. Bird CE, Rieker PP. Gender matters: an integrated model for understanding men's and women's health. Soc Sci Med 1999;48:745-55.

2. Wizemann TM, Pardue M-L. Exploring the biological contributions to human health: does sex matter? The National Academies Press, 2001.

3. Waldron I. Trends in gender differences in mortality: relationships to changing gender differences in behaviour and other causal factors. In: Annandale E, Hunt K. eds Gender inequalites in health. Buckingham: Open University Press, 2000:150-81.

4. McCartney G, Mahmood L, Leyland AH, et al. Contribution of smoking-related and alcohol-related deaths to the gender gap in mortality: evidence from 30 European countries. Tob Control 2011;20:166-8.

5. Briscoe ME. Why do people go to the doctor? Sex differences in the correlates of GP consultation. Soc Sci Med 1987;25:507-13.

6. Banks I. No man's land: men, illness, and the NHS. BMJ 2001;323:1058-60.

7. Hippisley-Cox J, Vinogradova Y. Trend in consultation rates in general practice 1995 to 2008: analysis of the QRESEARCH database: the NHS Information Centre, 2009.

8. McCormick A, Fleming DM. Morbidity statistics from general practice: fourth national study 1991-1992. London: HMSO, 1995.

9. Rowlands O, Singleton N, Maher J, et al. Living in Britain: results from the 1995 General Household Survey. London: Office for National Statistics 1996.

10. Sattar G, Glen F, Diaper A. General Household Survey 2004 : overview report. London: Office for National Statistics 2005.

11. Walker A, O'Brien M, Traynor J, et al. Living in Britain: results from the 2001 General Household Survey. London: HMSO, 2002.

12. Office for National Statistics. General Lifestyple Survey: a report on the 2009 General Lifestyle Survey. In: Dunstan S. ed. London: Office for National Statistics 2011.

13. Bertakis LD, Azari R, Helms J, et al. Gender differences in the utilization of health care service. J Fam Pract 2000;49:147-52.

14. Hollnagel $\mathrm{H}$, Kamper-Jrgensen $\mathrm{F}$. Utilisation of health services by 40-year-old men and women in the Glostrup area, Denmark. Danish Med Bull 1980;27:130-9.

15. Latinovic R, Gulliford M, Ridsdale L. Headache, and migraine in primary care: consultaion, prescription, and referral rates in a large population. J Neurol Neurosurg Pschiatry 2006;77:385-7.

16. Richards $\mathrm{H}, \mathrm{McC}$ nnachie A, Morrison $\mathrm{C}$, et al. Social and gender variation in the prevalence, presentation and general practitioner provisional diagnosis of chest pain. J EpidemiolCommunity Health 2000;54:714-18.

17. Vegda V, Nie J, Wang L, et al. Trends in health services utilization, medication use, and health conditions among older adults: a 2-year retrospective chart review in a primary care practice. BMC Health Serv Res 2009;9:217. 
18. Hunt K, Adamson J, Hewitt C, et al. Do women consult more than men? A review of gender and consultation for back pain and headache. J Health Serv Res Policy 2011;16:108-17.

19. Hunt K, Ford G, Harkins L, et al. Are women more ready to consult than men? Gender differences in family practitioner consultation for common chronic conditions. J Health Serv Res Policy 1999;4:96-100.

20. Bendelow G. Pain perceptions, emotions and gender. Sociol Health IIIn 2008;15:273-94.

21. Galdas PM, Cheater F, Marshall P. Men and health help-seeking behaviour: literature review. J Adv Nurs 2005;49:616-23.

22. Townsend $\mathrm{A}$, Wyke S, Hunt K. Frequent consulting and multiple morbidity: a qualitative comparison of 'high' and 'low' consulters of GPs. Fam Pract 2008;25:168-75.

23. Galdas $P$, Cheater $F$, Marshall $P$. What is the role of masculinity in white and South Asian men's decisions to seek medical help for cardiac chest pain? J Health Serv Res Policy 2007;12:223-9.

24. O'Brien R, Hunt K, Hart G. 'It's caveman stuff, but that is to a certain extent how guys still operate': men's accounts of masculinity and help seeking. Soc Sci Med 2005;61:503-16.

25. Department of Health. Department of Health: Departmental Report 2008-The Health and Personal Social Services Programmes. London, 2008.

26. Bertakis KD, Azari R, Helms LJ, et al. Gender differences in the utilization of health care services. J Fam Pract 2000;49:147-52.

27. Statistics Canada. How healthy are Canadian: the health divide: how the sexes differ. Health Rep 2001;12:33-9.

28. van Wijk CMT, Kolk AM, van Den Bosch WJHM, et al. Male and female morbidity in general practice: the nature of sex differences. Soc Sci Med 1992;35:665-78.

29. Adamson J, Ben-Shlomo Y, Chaturvedi N, et al. socio-economic position and gender-do they affect reported health-care seeking behaviour? Soc Sci Med 2003;57:895-904.

30. Cegedim. Cegedim Strategic data: Data, 2012.

31. Blak BT, Thompson M, Dattani H, et al. Generalisability of The Health Improvement Network (THIN) database: demographics, chronic disease prevalence and mortality rates. Inform Prim Care 2011;19:251-5.

32. Bourke A, Dattani H, Robinson M. Feasibility study and methodology to create a quality-evaluated database of primary care data. Inform Prim Care 2004;12:171-7.

33. Horsfall L, Walters K, Petersen I. Identifying periods of acceptable computer usage in primary care research databases. Pharmacoepidemiol Drug Saf 2013;22:64-9.
34. Maguire A, Blak BT, Thompson M. The importance of defining periods of complete mortality reporting for research using automated data from primary care. Pharmacoepidemiol Drug Saf 2009;18:76-83.

35. Dave S, Petersen I. Creating medical and drug code lists to identify cases in primary care databases. Pharmacoepidemiol Drug Saf 2009;18:704-7.

36. British National Formulary. Chapter 2: cardiovascular system; chapter 4: central nervous system. British National Formulary: RPS Publishing, 2007:70.

37. Gijsbers van Wijk CM, Kolk AM, van den Bosch WJ, et al. Male and female health problems in general practice: the differential impact of social position and social roles. Soc Sci Med 1995;40:597-611.

38. Verbrugge LM. Gender and health: an update on hypotheses and evidence. J Health Soc Behav 1985;26:156-82.

39. Wyke S, Hunt K, Ford G. Gender differences in consulting a general practitioner for common symptoms of minor illness. Soc Sci Med 1998;46:901-6.

40. Sayer GP, Britt H. Sex differences in prescribed medications: another case of discrimination in general practice. Soc Sci Med 1997;45:1581-7.

41. Adams A, Buckingham CD, Lindenmeyer A, et al. The influence of patient and doctor gender on diagnosing coronary heart disease. Sociol Health IIIn 2008;30:1-18.

42. Arber S, McKinlay J, Adams A, et al. Influence of patient characteristics on doctors' questioning and lifestyle advice for coronary heart disease: a UK/US video experiment. Br J Gen Pract 2004;54:673-8.

43. Arber S, McKinlay J, Adams A, et al. Patient characteristics and inequalities in doctors' diagnostic and management strategies relating to CHD: a video-simulation experiment. Soc Sci Med 2006;62:103-15.

44. Hunt K, Adamson J, Galdas P. Gender and help-seeking: towards gender-comparative studies. In: Kuhlmann E, Annandale E. eds Handbook of gender and healthcare. London: Palgrave, 2010:207-21.

45. Smith SM, Campbell NC, MacLeod U, et al. Factors contributing to the time taken to consult with symptoms of lung cancer: a cross-sectional study. Thorax 2009;64:523-31.

46. Gerritsen AA, Deville WL. Gender differences in health and health care utilisation in various ethnic groups in the Netherlands: a cross-sectional study. BMC Public Health 2009;9:109.

47. Henderson JT, Weisman CS. Physician gender effects on preventive screening and counseling: an analysis of male and female patients' health care experiences. Med Care 2001;39:1281-92. 